\title{
Ovine Fetal-Maternal Water Transfer is Independent of Fetal Prolactin Levels ${ }^{1}$
}

\author{
ROSEMARY D. LEAKE, M. GORE ERVIN, MICHAEL G. ROSS, DANIEL H. POLK, \\ ROBERT LAM, AND DELBERT A. FISHER \\ Department of Pediatrics and Obstetrics, UCLA School of Medicine, Harbor/UCLA Medical Center, \\ Torrance, California 90509
}

\begin{abstract}
To examine the effect of prolactin (PRL) on transplacental water flow, we infused mannitol $(500 \mathrm{ml}$; $20 \%$ solution) over 10 min into five chronically catheterized ewes (121-134 days' gestation), producing a peak maternal plasma osmolality by $10 \mathrm{~min}$ and fetal osmolality by 20 min. One day before or after, an identical amount of mannitol was infused into the same ewe during the 2 nd $h$ of a 2-h infusion of PRL (40 $\pm 2.2 \mu \mathrm{g} / \mathrm{h})$ into a fetal leg vein. Mean $( \pm S E)$ fetal plasma PRL levels were $6.9 \pm 3.2$ $\mathrm{ng} / \mathrm{ml}$ at baseline. Steady state fetal PRL levels were 17.7 $\pm 7.4 \mathrm{ng} / \mathrm{ml}$ during PRL infusion. Maternal mannitol infused without administration of PRL to the fetus evoked a rise in fetal plasma osmolality similar to that following maternal mannitol during PRL administration to the fetus. Thus, as shown previously, PRL affects water permeability across the membranous chorioamnion, whereas results of the present study indicate that the hormone does not affect water transfer across the ovine chorionic villi (placenta). (Pediatr Res 19: 986-988, 1985)
\end{abstract}

\section{Abbreviations}

AF, amniotic fluid

PRL, prolactin

AVP, arginine vasopressin

The importance of PRL in osmoregulation in fish and some mammals is well recognized. In these species PRL appears to act on several sites of hydromineral exchange including the fish gill, bladder, intestinal mucosa, and avian salt gland. Several recent studies also suggest that PRL plays a role in mammalian water homeostasis during pregnancy (1-11). PRL is found in high concentrations in human amniotic fluid (approximately $400 \mathrm{ng} /$ $\mathrm{ml}$ at term) although its function remains unclear. In pregnant women plasma PRL concentrations increase throughout gestation, with a return to basal levels by one week following delivery (1). PRL levels in human fetal plasma are relatively low before $25 \mathrm{wk}$ but increase rapidly in the $3 \mathrm{rd}$ trimester; the mean value at term approximates $200 \mathrm{ng} / \mathrm{ml}(9)$. In comparison to human AF levels, PRL levels are low in ovine amniotic fluid throughout gestation (approximately $10 \mathrm{ng} / \mathrm{ml}$ ). PRL is present in ovine fetal blood in increasing concentrations from 90 days gestation with a sharp increase after 110 days gestation; at term the mean value

Received September 10, 1984; accepted April 24, 1985.

Reprint requests Rosemary D. Leake, M.D., Department of Pediatrics, Harbor/ UCLA Medical Center, 1000 West Carson Street, Torrance, CA 90509.

Supported by the United States Public Health Services Grant HD-06335 from the National Institute of Child Health and Human Development and NIH Grant RR-00425.

${ }^{1}$ Presented in part at the Thirty-First Annual Meeting of the Society for Gynecologic Investigation, San Francisco, CA, March 21-24, 1984. has been reported to approximate $35 \mathrm{ng} / \mathrm{ml}(8,9)$. Thus, although there are quantitative differences, the ontogenic pattern for ovine fetal plasma PRL is similar to that of the human fetus.

PRL has been identified as one of the hormones affecting AF water dynamics. In vitro studies by Leontic and Tyson (6), Holt and Perks (2), and Manku et al. (3) have shown that PRL affects diffusional water transfer across the isolated amniotic membrane, although the direction of this hormonally influenced water transfer may differ from species to species. Additionally, we have shown in vivo that elevated ovine AF PRL levels diminish bulk flow of water across the chorioamnion from the amniotic fluid to maternal circulation in response to acute changes in maternal osmolality (11). Also we have shown that following maternal mannitol infusion, fetal to maternal water transfer across the ovine placenta is diminished by fetal AVP or arginine vasotocin (10). The object of the present study was to determine whether, like AVP and arginine vasotocin, fetal PRL affects osmotically induced (bulk flow) water transfer across the ovine chorionic villi (placenta) as it does across the membranous chorioamnion.

\section{MATERIALS AND METHODS}

Five date-bred healthy (Columbia-Suffolk) ewes with singleton fetuses of 116-126 days' gestation were studied. A maternal hysterotomy was carried out under ketamine anesthesia. A single fetal hind limb was exteriorized. Polyethylene catheters were inserted into the fetal dorsal leg vein and artery and advanced to the inferior vena cava and aorta, respectively. The fetus was then replaced in the uterus, the fetal catheters were exteriorized to a pouch attached to the flank of the ewe, and the uterus and maternal abdominal wall were closed. Maternal femoral venous and arterial catheters also were placed. Catheters were maintained patent with a dilute heparin solution. At least 5 days were allowed for recovery from surgery. Chloramphenicol $(250 \mathrm{mg})$ was given intravenously to the ewe and instilled into the amniotic cavity $(250 \mathrm{mg})$ twice daily. Animals were maintained in indoor pens and allowed access to baled alfalfa and water ad libitum. Gestational age at the time of studies ranged from 121-134 days.

On the day of study, drinking water was removed from the cage. Studies were conducted only if the fetal arterial $\mathrm{pH}$ exceeded 7.3. Twenty-four $\mathrm{ml}$ whole blood were removed from the maternal circulation into a heparinized syringe for subsequent fetal replacement transfusion.

In protocol I (mannitol control), three baseline blood samples ( $3 \mathrm{ml}$ each) were obtained at 10 -min intervals from both fetal and maternal arterial catheters for plasma osmolality determinations. All samples were collected only after three times the dead space volume of the catheter ( 1 and $2 \mathrm{ml}$, fetal and maternal, respectively) was withdrawn. After baseline blood samples were obtained, $500 \mathrm{ml}$ mannitol were infused via the maternal venous catheter over $10 \mathrm{~min}$. After the completion of the mannitol infusion, five $(3 \mathrm{ml})$ blood samples were obtained from the 
maternal and fetal arterial catheters at 10-min intervals. Throughout the study, each maternal sample was replaced with an equal quantity of isotonic saline; each fetal sample was replaced with an equal volume of maternal heparinized whole blood prepared prior to the study, and the dead space volume of fetal blood and flush solution was reinfused.

One day before or after the protocol I study, protocol II (mannitol during fetal PRL infusion) was performed in the same animals. After obtaining three baseline blood samples at 10 -min intervals, ovine PRL [Ovine PRL, National Institutes of Health, (lot no. 14), Bethesda, MD] $(40 \pm 2.2 \mu \mathrm{g} / \mathrm{h})$ was infused for $2 \mathrm{~h}$ into the fetal vein. Blood samples $(3 \mathrm{ml}$ each) were obtained every $10 \mathrm{~min}$ from both the fetus and ewe throughout the PRL infusion period, with blood replacement as described previously. At the completion of the $1 \mathrm{st} h$ of the fetal PRL infusion, mannitol was infused into the mother ewe via the femoral venous catheter in a manner identical to protocol I.

Both fetal and maternal blood samples $(3 \mathrm{ml})$ were collected in iced tubes containing 15\% EDTA. Samples were centrifuged and the plasma separated. One-ml plasma samples were stored at $-20^{\circ} \mathrm{C}$ for measurement of osmolality determined by freezing point depression using an Advanced Instruments 3R Precision Osmometer. The remaining plasma was stored at $-20^{\circ} \mathrm{C}$ for measurement of plasma sodium levels by flame photometry and plasma prolactin by radioimmunoassay $(12,13)$. Ovine PRL concentrations were determined by radioimmunoassay utilizing purified ovine PRL and antisera obtained from the National Institute of Arthritis, Diabetes and Kidney Disease. National Institute of Arthritis, Diabetes and Kidney Disease oPRL-I-1 was used both as standard and for iodination. The oPRL was iodinated with $\mathrm{Na}^{125} \mathrm{I}$ and Iodogen (Pierce Chemical Co.) and the labeled fraction was separated using Sephadex G-75 (Pharmacia). National Institute of Arthritis, Diabetes and Kidney Diseaseanti-oPRL-1 antiserum was used as the first antibody.

Mean values for the baseline and poststimulation (postmannitol) study periods were compared using the paired $t$ test. Comparisons between groups for protocols I and II were made by 2 -way analysis of variance. Values were expressed as mean \pm SEM.

\section{RESULTS}

The baseline (mean \pm SEM) fetal plasma PRL level was $6.9 \pm$ $3.2 \mathrm{ng} / \mathrm{ml}$. The mean infusion steady state plasma oPRL level was $17.7 \pm 7.4 \mathrm{ng} / \mathrm{ml}$. Figure 1 shows the fetal osmolal response to maternal mannitol infusion with and without concurrent fetal PRL infusion. In protocol $\mathrm{I}$, mean $( \pm$ SEM) fetal baseline os-

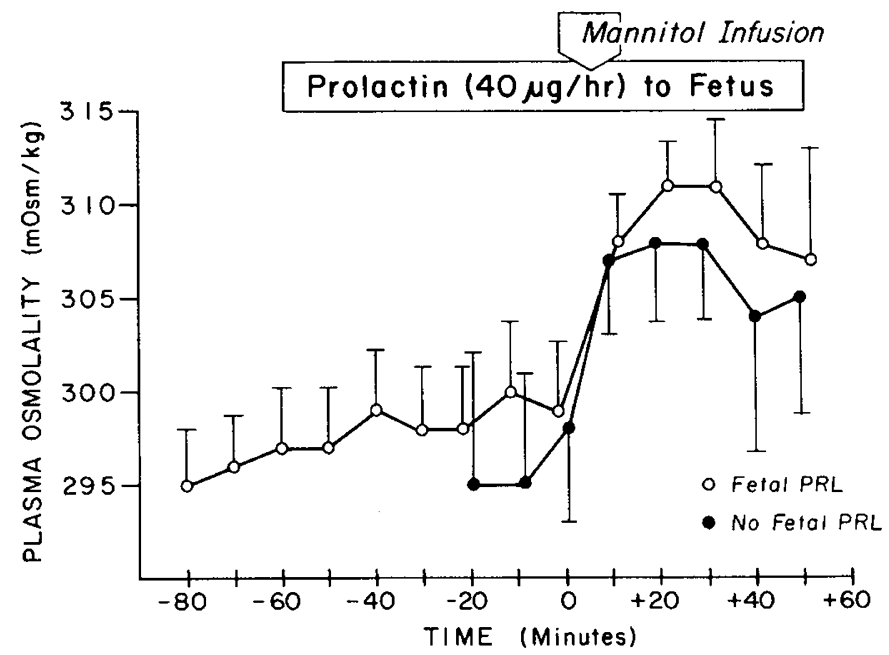

Fig. 1. Plasma osmolality responses in five ovine fetuses following maternal mannitol ( $500 \mathrm{ml} ; 20 \%$ solution) infusion with and without fetal PRL infusion $(40 \mu \mathrm{g} / \mathrm{h})$. Data are expressed as the mean $\pm \mathrm{SEM}$. molality was $294 \pm 2.4 \mathrm{mosmol} / \mathrm{kg}$ prior to mannitol infusion to the ewe. Following the maternal mannitol infusion, mean fetal osmolality increased to $307 \pm 1.7$ mosmol $(p<0.05$, baseline versus postmannitol).

In Protocol II, mean baseline fetal osmolality was $296 \pm 2.0$ mosmol/ $\mathrm{kg}$ and did not change during the $1 \mathrm{st} \mathrm{h}$ of fetal PRL infusion (298 $\pm 2.2 \mathrm{mosmol} / \mathrm{kg}$ ). Fetal plasma osmolality following mannitol infusion (during fetal PRL infusion) increased to $309 \pm 2.2 \mathrm{mosmol} / \mathrm{kg}$. Both mean baseline and mean postmannitol osmolality values were statistically similar in protocols I and II. The mean baseline fetal plasma sodium $(147 \pm 0.6 \mathrm{mEq} /$ L) was unchanged during the $1 \mathrm{st} h$ of fetal PRL infusion (146 \pm $0.5 \mathrm{mEq} / \mathrm{L}$ ). There was a significant but comparable increase in mean plasma sodium level 50 and $60 \mathrm{~min}$ after the mannitol infusion to the ewe in those experiments with and without PRL infusion ( $153 \pm 3$ and $154 \pm 2.5 \mathrm{mEq} / \mathrm{L}$, respectively).

\section{DISCUSSION}

In the present study fetal PRL infusions produced plasma PRL levels approximately double baseline fetal PRL concentrations. Thus we produced physiologic rather than pharmacologic plasma PRL levels (8). Although plasma levels of PRL have been measured previously in the chronically catheterized ovine fetus (8), PRL receptors have been identified only in cell membranes of a variety of adult rhesus monkey tissues, including liver, lung, myocardium, and placenta. Less is known about ovine PRL receptors. Ovine PRL receptors are likely, however, since we previously reported that amniotic to maternal water transfer across the chorioamnion in response to a maternal osmotic challenge is diminished in the presence of elevated AF PRL levels (11). In the rhesus monkey high levels of PRL in AF: 1) tend to minimize any increase in fetal electrolyte concentration during conditions of experimentally induced hypertonicity, and 2) inhibit fetal losses of electrolytes and water when AF hypotonicity is induced (5). In contrast, Leontic and Tyson (7) reported that maternal to fetal transport of tritiated water is not affected in vitro by PRL. Moreover, AF PRL has little or no effect on water transport by fetal skin (7). Additionally, in the present study elevated fetal PRL levels had no apparent effect on transplacental flow of water from the fetal to the maternal circulation (presumably at the level of the chorionic villi "placenta") in response to acutely induced maternal plasma hyperosmolality. These data, in total, suggest that the primary osmoregulatory site of action for PRL may be the membranous chorioamnion.

The PRL used for these studies is known to be contaminated with minimal amounts of AVP; however Leontic and Tyson (7) have shown that AVP in concentrations far exceeding those contaminating ovine PRL preparations does not affect water transport (6).

This study explores another site of possible fetal hormonal influence on fetal/maternal/amniotic fluid water exchange in the mammal. The site(s) of action and the precise effects of various hormones may vary from species to species, perhaps depending on the type of placenta, ontogenic pattern of hormonal secretion, receptor sites, and other factors. In the ewe, however, the most convincing site of PRL effect appears to be the membranous chorioamnion.

\section{REFERENCES}

1. Tyson JE, Hwang P, Guyda H, Friesen HG 1972 Studies of prolactin secretion in human pregnancy. Am J Obstet Gynecol 113:14-20.

2. Holt WF, Perks AM 1975 The effect of prolactin on movement through the isolated amniotic membrane of the guinea pig. Gen Comp Endocrinol 26:153-164

3. Manku MS, Mtabaji JP, Horrobin DP 1975 Effect of cortisol, prolactin and $\mathrm{ADH}$ on the amniotic membrane. Nature 258:78-79

4. Josimovich JB, Merisko K, Boccella L, Tobon H 1977 Binding of prolactin on fetal rhesus cell membrane fractions. Endocrinology 100:557-570

5. Josimovich JB, Merisko K, Boccella L 1977 Amniotic prolactin control over amniotic and fetal extracellular fluid water and electrolytes in the rhesus monkey. Endocrinology 100:564-570 
6. Leontic EA, Tyson JE 1977 Prolactin and fetal osmoregulation: water transport across isolated human amnion. Am J Physiol 232:R 124-127

7. Leontic EA, Tyson JE 1977 Possible osmoregulatory role of amniotic fluid prolactin. In: Crosignani PG, Robyn C (eds) Prolactin and Human Reproduction. Academic Press, London, pp 37-45

8. Mueller PL, Gluckman PD, Kaplan SL, Grumbach MM 1979 Hormone ontogeny in the ovine fetus. V. Circulating prolactin in mid- and lategestation and the newborn. Endocrinology 105:129-134

9. Gluckman PD, Grumbach MM, Kaplan SL 1981 The neuroendocrine regulation and function of growth hormone and prolactin in the mammalian fetus. Endocrinol Rev 2:263-395

10. Leake RD, Stegner H, Palmer SM, Oakes GK, Fisher DA, Everett SL 1983
Arginine vasopressin and arginine vasotocin inhibit ovine fetal/maternal water transfer. Pediatr Res 17:583-586

11. Ross MG, Ervine MG, Leake RD, Oakes GK, Hobel CJ, Fisher DA 1983 Bulk flow of amniotic water in response to maternal osmotic challenge. Am $\mathbf{J}$ Obstet Gynecol 147:697-701

12. Tower BB, Clark BR, Rubin RT 1977 Preparation of ${ }^{125}$ I polypeptide hormones for radioimmunoassay using glucose oxidase with lactoperoxidase. Life Sci 21:959-966

13. Tower BB, Sigel MB, Rubin RT, Poland RE, Vander Laan WP 1978 The talcresin-TCA test: rapid screening of radioiodinated polypeptide hormones for radioimmunoassay. Life Sci 23:2183-2192 